\title{
A PRODUÇÃO DE CONHECIMENTO EM ENFERMAGEM EM UM CONTEXTO DESCENTRADO E ADVERSO ${ }^{1}$
}

\author{
THE KNOWLEDGE PRODUCTION ON NURSING ON A \\ DECENTRALIZED AND ADVERSE CONTEXT
}

\section{LA PRODUCIÓN DE CONOCIMIENTO EN ENFERMERÍA EN UN CONTEXTO DESCENTRALIZADO Y ADVERSO}

\author{
Wilza Rocha Pereira*
}

\begin{abstract}
RESUMO
Trata-se de uma reflexão teórica realizada com o objetivo de compreender alguns aspectos do processo de produção do conhecimento em enfermagem em um contexto descentrado e adverso. O estudo foi realizado a partir da problematização de conceitos ligados ao gênero e a idéia de campo científico de Bourdieu. Produzir conhecimentos científicos em enfermagem é, quase sempre, uma atividade feita por mulheres, que somam, com todas as demais atividades cotidianas, a de pesquisar. Assim as atividades de investigação são realizadas em conjunto com outros trabalhos o que faz com que ocorra a perda da prioridade e da objetividade, condições estas fundamentais para o sucesso no processo de produção do conhecimento e decisivas para a sobrevivência do pesquisador no campo científico. Neste sentido conhecer as adversidades e problematizálas sob algumas concepções teóricas mais flexíveis pode contribuir para a permanência das pesquisadoras enfermeiras no campo científico.
\end{abstract}

Palavras chave: Produção científica, enfermagem, identidade de gênero, ciência, método.

\begin{abstract}
This is a reflection with which I aimed to understand some of the aspects of the process of knowledge production on nursing, on a decentralized and adverse context. The study was problematized using concepts of gender and of Bourdieu's idea of scientific field. Producing scientific knowledge on nursing is generally an activity made by women, who add researching to all their further daily activities. For this activity we still lack many of the objective conditions that are fundamental for a successful knowledge production process, and also essential for surviving on the scientific field. On peripheral contexts, like the one we act, knowing the adversities and problematization from some flexible theoretical concepts, may contribute to our permanence on scientific field.
\end{abstract}

Key words: Scientific production, nursing, gender identity, science, method.

\footnotetext{
${ }^{1}$ Trabalho realizado durante o Estágio Pós-doutoral no Grupo de Estudos e Relações de Gênero (GEERGE) da Faculdade de Educação da Universidade Federal do Rio Grande do Sul, sob a supervisão da Profa Dra. Dagmar Estermann Meyer.

* Professor, Líder do Grupo de pesquisa Gestão e Formação em Enfermagem (GEFOR) da Faculdade de Enfermagem da UFMT. Bolsista de Pós-doutorado da FAPEMAT/MT. Email: wilzarp@gmail.com
} 


\section{RESUMEN}

Artículo que presenta una reflexión respecto a algunos aspectos del proceso de producción de conocimiento en enfermería en un contexto descentralizado y adverso. El estudio fue problematizado desde conceptos de género y desde la perspectiva teórica de campo científico de Bourdieu. La producción de conocimientos científicos en enfermería es, casi siempre, una actividad realizada por mujeres, donde investigar se suma a todas las demás actividades cotidianas. Para esta actividad aún nos faltan muchas condiciones objetivas fundamentales que significan el éxito en el proceso de generación de conocimiento, siendo también decisivas para la sobrevivencia en el campo científico. En contextos más periféricos como los que trabajamos, conocer las adversidades y las problematizaciones desde algunas concepciones teóricas más flexibles puede contribuir para la permanencia en el campo científico.

Palabras clave: Producción científica, enfermería, identidad de género, ciencia, método.

Fecha recepción: 16/08/11 Fecha aceptación: 22/03/12

\section{INTRODUÇÃO}

A temática sobre a qual incide meu interesse recai sobre a produção de conhecimentos científicos em enfermagem na Universidade Federal de Mato Grosso (UFMT), que será abordada em uma perspectiva que problematizará a produção de conhecimentos científicos na disciplina em questão e no contexto regional tendo por base teórica alguns aspectos da categoria teórica de gênero.

A enfermagem no país teve seu primeiro mestrado aprovado em 1972, na Escola de Enfermagem Ana Nery, no Rio de Janeiro, em seguida, em 1973, a Universidade de São Paulo criou o seu primeiro mestrado. Ambos no então chamado centro-sul do país. A criação deste primeiro curso de pós-graduação stricto sensu em enfermagem no país na Universidade de São Paulo foi entendida por algumas autoras da área como a 'garantia de permanência da enfermagem no mundo da universidade moderna' (1), uma vez que a pesquisa se fazia dentro da universidade e para ali permanecer e legitimar-se como uma ciência a enfermagem precisou organizar-se para oferecer também este nível de formação.

A relação entre a produção de conheci- mento e a universidade é muito estreita no nosso país e a Coordenação de Aperfeiçoamento de Pessoal de Ensino Superior (CAPES), órgão que regula o ensino neste nível no Brasil vem investindo nesta parceria, será objeto de um breve comentário ao longo do texto, para que possamos localizar o leitor sobre seu papel na criação e avaliação de novos cursos de pós-graduação stricto sensu e agora também atuando de forma ativa na qualificação dos periódicos nas diferentes áreas do conhecimento, veículos que são fundamentais para a circulação do que é avaliado como adequado aos padrões do exigente campo científico.

Na UFMT a pós-graduação no nível stricto sensu iniciou o primeiro curso de mestrado em agronomia no ano de 1993, 20 anos depois das outras instituições situadas no centro sul. $\mathrm{Na}$ enfermagem conseguimos as condições mínimas para instalar um mestrado apenas em 2005, quando teve a aprovação de seu curso que começou a funcionar em 2006. Por esta temporalidade alargada em relação ao centro sul, somada a outros aspectos, como a lenta capacitação do corpo docente local, o contexto de onde falo, regional e periférico, pode ser chamado também de adverso para a produção de conhecimento em todas as áreas. Mas, especificamente 
na enfermagem, este processo pode ser visto ainda como problemático, pois falamos de mulheres atuando no campo científico, historicamente ocupado pelos homens e dominado por um modelo de ciência que por quase dois séculos excluiu as mulheres, por julgá-las incapazes para a atividade científica.

São várias as explicações, mas vou montar meu argumento sobre três aspectos: falo desde a enfermagem, uma prática marcada pelo gênero e pelo feminino, composta em sua maciça maioria por mulheres que fazem/ realizam na realidade local duas práticas historicamente ligadas ao feminino, ensinar e, mais ou tão feminino quanto, ensinar a cuidar da saúde humana. Parte destas docentes, enfermeiras e agora doutoras na área, ao iniciar suas atividades na pós-graduação stricto sensu, adentraram o mundo das ciências da saúde, onde foram demandadas para uma nova atividade, que é a de produzir conhecimentos científicos em enfermagem e também em saúde.

Mesmo com todas as dificuldades e limites que a nova atividade impõe, estas pesquisadoras vem se esforçando para se manter no chamado campo científico, onde a luta pelo monopólio da competência científica é acirrada e cada vez mais transformada em um

'sistema de relações objetivas entre posições adquiridas (em lutas anteriores), é o lugar, o espaço de jogo de uma luta concorrencial. O que está em jogo especificamente nesta luta é o monopólio da autoridade científica, definida, de maneira inseparável, como capacidade técnica e poder social; ou, quisermos, o monopólio da competência científica, compreendida enquanto capacidade de falar e agir legitimamente (isto é, de maneira autorizada e com autoridade), que é socialmente outorgada a um agente determinado' (2).

Me pergunto: quais foram as posições adquiridas pelas enfermeiras em lutas ante- riores neste campo? Me parece que esta luta vem acontecendo agora, pois a enfermagem brasileira entrou neste 'jogo' ou nesta 'luta concorrencial' há menos de 40 anos enquanto outras áreas próximas, como a medicina, a saúde coletiva, não só estão há longo tempo dentro do campo, como ajudaram a construir suas normas e regras. É uma atividade para a qual as enfermeiras ainda estão adquirindo 'savoir-faire', tanto nos aspectos políticos do jogo, como nos aspectos técnico-científicos, estes fortemente validados pelos métodos que são utilizados ao produzir conhecimentos denominados como científicos.

Os conhecimentos que as cientistas da enfermagem vem produzindo pouco tem abalado o 'monopólio da autoridade científica', definida na saúde dentro de outra área, que advoga para si a 'capacidade técnica' para tal produção. A enfermagem ainda produz um tipo de conhecimento que parece não ser legítimo na grande área da saúde, que é pouco incorporado no cotidiano das práticas mesmas da enfermagem, o que não nos ajuda na defesa de ser este um conhecimento necessário e viável.

Estamos longe de deter na grande área da saúde 'o monopólio da competência científica', e ainda não falamos e tampouco agimos como os que historicamente já adquiriram autoridade e legitimidade para falar e nome de grande área e desqualificar os demais conhecimentos a tal ponto de criar entraves para sua concretização nas práticas dentro dos serviços.

Os conhecimentos que nós enfermeiras cientistas produzimos para alimentar as nossas práticas cotidianas, sofrem um processo de invisibilização mesmo por nós, de dentro da enfermagem. Este é um problema de natureza tão candente e difícil que ainda pouco conseguimos descrever concretamente como os incorporamos/transferimos para as nossas práticas cotidianas de enfermagem (2).

O processo de transferência de vem sendo 
há pouco tempo problematizado na enfermagem brasileira, e entendo que para efetivamente utilizar nas nossas práticas cotidianas os conhecimentos que produzimos na enfermagem, precisamos pensar nas condições materiais e simbólicas que estão dadas dentro dos serviços para que ocorra este processo, nem sempre causado, como parece a primeira vista por má vontade ou desconhecimento por parte das equipes de enfermagem que atuam nos mais diversos serviços de saúde (3).

Há todo um movimento realizado pelos diferentes sujeitos que circulam nos serviços de saúde que faz com que alguns conhecimentos sejam rapidamente incorporados e outros não. Este movimento, pode-se dizer, é subjacente às práticas técnicas e entra no campo das práticas políticas que pode, efetivamente, impedir ou permitir que determinadas atividades tomem corpo, se materializem dentro dos serviços. Precisamos na enfermagem, como diz uma estudiosa de gênero, 'avançar na compreensão da relação dialética, de determinação mútua, entre o simbólico e o material, e entre o subjetivo e o objetivo, na conformação da dominação e sua superação' (4).

Em tese de livre docência foi apontado que os obstáculos para a utilização do conhecimento produzido por enfermeiras estão relacionados prioritariamente às instituições de saúde e, apenas, secundariamente à fatores relacionados ao desejo da profissional de enfermagem (5), que vê necessidade de melhorar suas práticas pela incorporação de resultados de pesquisas mas que há pouco ou mesmo nenhum incentivo ou facilitação deste processo pelos gestores dos serviços de saúde. Há, pelo contrário, muitas dificuldades e diversos impedimentos para a introdução das inovações vindas ou produzidas pela enfermagem, ainda que estas sejam de baixo custo ou mesmo sem custo financeiro, do que das tecnologias ou inovações de alto custo produzidas nas áreas mais tradicionais dentro dos serviços de saúde, cada vez mais onerosos por este fato específico: o alto custo das inovações trazidas por uma área que ainda é dominante na saúde e que não é a enfermagem (5).

Compreender que apenas enormes esforços não são suficientes para garantir a sobrevivência no mundo científico quando falamos de produção de conhecimento por enfermeiras pesquisadoras é apenas o primeiro passo para diminuir a segregação horizontal e vertical sobre a qual falaremos a seguir e que me parece, existe de forma muito concreta no contexto da produção do conhecimento em enfermagem dentro da grande área da saúde.

Como o objetivo desta reflexão foi a compreensão de alguns aspectos do processo de produção de conhecimento em enfermagem em um contexto muito específico e localizado, mas em muito semelhante a grande maioria dos demais que se situam nos outros estados, penso que precisamos, como grupo de enfermeiras pesquisadoras ter o cuidado de não só identificar mas sobretudo problematizar e politizar o debate sobre o que nos tolhe e nos fragiliza no processo de produção de conhecimento científico no mundo da saúde.

Esta reflexão caminha neste sentido e foi realizada durante o estagio pós-doutoral e parte de em um projeto maior que ainda está em curso e que visa proporcionar elementos para repensar nosso lugar e os muitos esforços que ainda teremos que fazer para produzir e fazer circular conhecimentos na nossa área de estudos, ainda nas margens/fronteiras das consagradas ciências da saúde.

\section{ENFERMAGEM, PRODUÇÃO DE CONHECIMENTO, CIÊNCIAS: UMA QUESTÃO DE GÊNERO?}

A enfermagem é a segunda maior categoria de nível superior na saúde com 14,9\%, os primeiros são os médicos, com $67,8 \%$. A 
diferença marcante que isso expressa é que a quase totalidade das profissionais de nível superior na enfermagem são mulheres.

Há desde a fundação da enfermagem moderna, por Florence Nightingale no final do século XIX, uma acentuada feminização na categoria. Esta sempre foi marcada por conteúdos fortemente ideológicos, permeada pelo discurso religioso, nos quais eram enfatizados o devotamento, o idealismo, o altruísmo e o desprendimento material, discursos estes que começaram a ser questionados/ desconstruídos a partir dos primeiros estudos que abordaram a enfermagem desde a perspectiva de gênero (6).

Nas últimas quatro décadas, as estudiosas feministas levaram para a academia temas e fontes de investigação até então concebidas como menores e não autorizados pelo paradigma científico vigente, podendo-se mencionar temáticas e fontes vinculadas ao cotidiano, à família, a sexualidade e ao trabalho doméstico, dentre outras (7).

O crescimento de estudos de gênero voltados para a categoria de enfermagem contribuiu para que estas temáticas pudessem começar a fazer parte de seus estudos e pesquisas, e ajudou a desnaturalizar as associações entre enfermagem e religião, enfermagem e domesticidade, cuidado e feminino, cura e cuidado, dentre outros binarismos que por muito tempo nos limitaram na compreensão da nossa prática e do nosso espaço nos sistemas de saúde.

Mesmo tendo ampliado a consciência crítica das profissionais com relação à estas questões, os estudos de gênero não tem a prerrogativa de impedir que ocorra o fenômeno da segregação que percebemos ocorre com os conhecimentos produzidos por cientistas enfermeiras, mas vários movimentos vem sendo feitos para melhor compreender como se pensa o conhecimentos produzidos por mulheres em todas as áreas.

$\mathrm{Na}$ leitura dos textos apresentados nas mesas de debates e nas recomendações finais do Encontro Nacional de Núcleos e Grupos de Pesquisa - Pensando Gênero e Ciências, ocorrido em Brasília, em março de 2006, fui colocada em contato com as idéias de pesquisadoras (es) e estudiosas (os) de mais de 200 núcleos e grupos de pesquisa de cerca de 100 universidades de todo o país, que discutiram e analisaram o campo de estudos de gênero no Brasil com a finalidade de não só estimular a produção acadêmica na área, mas de propor medidas e ações que contribuíssem para ampliar a inserção das mulheres em todos os campos da ciência e, ao mesmo tempo, discutir a trajetória das mulheres e seu posicionamento nas carreiras acadêmicas (8).

Durante muito tempo, as mulheres estiveram "ausentes" do mundo da ciência. Isso não significa dizer que inexistissem mulheres participando da produção do conhecimento científico [...] O resgate de realizações de grandes mulheres foi necessário para contrapor a noção de que elas não teriam capacidade para fazer ciência, noção esta embasada por teorias biomédicas sobre diferenças anatômicas ou fisiológicas em relação aos homens, que limitariam seu potencial intelectual e as conformariam exclusiva ou prioritariamente para a maternidade (9).

As enfermeiras cientistas ainda sofrem dificuldades para se posicionar e obter legitimidade em relação a algumas das áreas que constituem o amplo campo das ciências da saúde (6).

Há duas formas de segregação no conhecimento produzido por estas profissionais de saúde, a horizontal e a vertical, sendo que a primeira se dá no fenômeno mesmo da não incorporação nas práticas cotidianas do conhecimento produzido pelas enfermeiras e a segunda se situa no entorno das relações de poder que se articulam na saúde, onde as mulheres tem dificuldade a ter acesso aos cargos mais elevados, o que é particularmen- 
te acentuado quando nos voltamos para os órgão de fomento ou institutos de pesquisa na área (9).

No ensino superior as mulheres são maioria entre os alunos matriculados (56,3\%) e concluintes (64,2\%) [...] em 2002 elas já eram maioria entre os que receberam bolsas de Iniciação Científica e mestrado (respectivamente $55,1 \%$ e $52,9 \%$ ) receberam quase a metade das bolsas de doutorado $(48,4 \%)$ e recém-doutor (49,7\%). Porém enquanto que as bolsas no país tem distribuição equilibrada, quando se trata de bolsas no exterior, estas são majoritariamente utilizadas por homens (63,5\% em doutorado e 78,2\% em pós-doutorado). Além disso, a grande maioria das bolsas de produtividade em pesquisa $(67,8 \%)$ é destinada à eles, o que se acentua em um nítido gradiente à medida em que aumenta $\mathrm{o}$ nível hierárquico (9).

É meu entendimento que o fenômeno da segregação horizontal ocorre tanto dentro da enfermagem como pelo fato de que as enfermeiras adotam metodologias menos ortodoxas para seus estudos quando comparados àqueles de cunho mais instrumental, como são os estudos epidemiológicos, quantitativos e que cobrem grandes amostras populacionais que utilizam métodos bem mais tradicionais reconhecidos como 'mais científicos' que os 'outros', onde se situam os que adotamos, com maior freqüência na enfermagem.

As diferenças são acentuadas nas atividades científicas, com as mulheres médicas tendendo a participar menos de eventos e de publicações científicas, principalmente à medida que aumenta o número de filhos ou quando estes ainda são mais dependentes, o que não é diferente com as enfermeiras, fato que pode se tornar relativamente problemático quando temos uma categoria que é em mais de $90 \%$ composta por mulheres. São muito mais mulheres com muito menos condições objetivas de produção de conheci- mento, mas, mesmo assim, produzindo.

O que se vê, então, é que a dupla jornada torna o tempo das mulheres cientistas mais escasso e fragmentado. E o tempo na vida acadêmica é crucial: para elaborar projetos e obter financiamentos; para produzir e escrever artigos, formatá-los e submetê-los; atender a exigências; receber críticas, enfrentá-las e rebatê-las, enfrentar recusas e reiniciar o ciclo buscando novas alternativas. Adicionalmente, a socialização das mulheres para docilidade e submissão introjeta barreiras subjetivas que dificultam o enfrentamento de editores, pareceristas. Tudo isso ocorre sem que a comunidade científica admita reconhecer as diferenças de gênero nas práticas de pesquisa. Se além de tudo, a participação das mulheres resulta em mudanças no modo de produzir conhecimento, elegendo-se novos temas e questões, revendo-se teorias e conceitos, incorporando-se novos meios de investigar os problemas, redobram-se as dificuldades. Afinal, a luta cotidiana pela legitimação de novos campos e abordagens demanda muito tempo e energia criativa (9).

E como pensar a produção de conhecimentos em enfermagem em um contexto periférico e descentrado como o que origina esta reflexão? Se pensarmos desde os processos de socialização de gênero, vemos que este conforma as escolhas profissionais e delimita horizontes de possibilidades de homens e mulheres, que precisam atender a diferentes expectativas sociais e familiares. Nestes arranjos sociais as mulheres quase sempre é dado um leque mais limitado de escolhas e elas enfrentam dificuldades adicionais em um ambiente competitivo como é o da ciência, no qual "a agressividade masculina é interpretada positivamente com assertividade e a assertividade feminina é julgada negativamente como autoritarismo" (9).

$\mathrm{Na}$ enfermagem este fenômeno toma outra forma, pois são as enfermeiras a maioria absoluta da categoria e são elas que produ- 
zem conhecimento e tomam as decisões sobre objetos, temáticas, métodos, teorias em que se embasarão. Quando passamos a problematizar o nosso principal objeto de estudo o cuidado humano, nova questão se coloca, pois esse historicamente está mais próximo de um modelo de ciência que não se adapta aos modelos mais tradicionais de ciências.

O mundo da ciência e da produção de conhecimentos situa-se no espaço público, nas universidades e institutos de pesquisa e é ainda dominado por uma racionalidade de cunho instrumental, onde se valoriza a produção de verdades, a objetividade, a separação sujeito/objeto para garantir a neutralidade dos conhecimentos e descobertas ali realizadas.

Como pensar a produção de conhecimentos em enfermagem, feita no entorno do cuidado, por mulheres em um contexto periférico e em uma área como a da saúde? Penso que precisamos, sendo enfermeiras e 'cientis$\operatorname{tas}^{22}$ de bases mais flexíveis e conceitos mais condizentes para se estudar as (muitas) diferenças, os fragmentos, as individualidades, as subjetividades que este processo aporta (10).

\section{CONSIDERAÇÕES FINAIS}

O pequeno grupo de docentes que passou a fazer parte da pós-graduação stricto sensu onde se concentra a produção de conhecimento em enfermagem local começou a perceber que outra linguagem, bem diferente daquela que nos constituiu como professores na graduação em enfermagem mas que vem circulando e tornando-se cada vez mais comum nos corredores da nossa faculdade: 'preciso publicar', 'tenho que pensar uma

\footnotetext{
${ }^{2}$ As aspas foram colocadas pela autora, com intuito de reforçar um certo incômodo que parece haver na associação 'enfermeira-cientista'. Esta associação remete a inúmeras possibilidades/idéias sobre novas formas de pensar a enfermagem e a ciência.
}

nova pesquisa' 'onde conseguir financiamento?', 'como vai ser a avaliação do programa se não publicarmos?'

Há hoje, no local do estudo, um peso maior sobre o grupo de docentes que atua na pós-graduação stricto sensu, nível mestrado e que aspira iniciar aqui um doutorado e talvez ser uma referência para o ensino de pósgraduação na realidade local. A nova atividade de assumir um curso de pós-graduação stricto sensu por movimentos diversos, ora intercalados, ora imbricados um com o outro, veio acrescentar dúvidas e incertezas sobre o que se fazia na graduação e sobre o que se produzia como pesquisa e ainda como se ensinava na graduação em enfermagem. Este movimento desejado na academia não acontece sem desconfortos e confrontos.

Criaram-se cisões entre os docentes que assumiram a nova atividade, novos agrupamentos foram compostos e outros desfeitos. $\mathrm{O}$ processo de conduzir a nova atividade caminha em meio a alguns poucos consensos e a muitos dissensos que nos obrigam a novos movimentos, ora de fuga ora de aproximação entre os diferentes sujeitos e grupos, em um processo que é dinâmico, criativo e, muitas vezes, cansativo. Mas ainda assim há um claro entendimento por parte de alguns docentes do grupo sobre os múltiplos desdobramentos e a riqueza das novas problematizações que a todo momento surgem no horizonte de nosso contexto local, que passa a ficar menos adverso e mais conhecido em suas novas demandas.

Elaborar este texto me permitiu aproximar-me e melhor problematizar nosso contexto local. A intenção é que ele contribua para que possamos não só seguir em frente nos nossos desejos, mas, sobretudo, através do conhecimento dos nossos limites desenvolver novas estratégias para compreender e para enfrentar as adversidades e conseguir permanecer no campo científico e, a partir dele, produzir mais conhecimentos em enfermagem que melhorem a qualidade das nossas práticas de saúde, ensino e pesquisa. 


\section{REFERÊNCIAS}

1. Miyadahira AMK, Silva MJP, Egry EY. [editorial]. A Pós-Graduação stricto sensu em Enfermagem comemora 30 anos! Rev Esc Enferm USP. 2004; 38(1): 7.

2. Ortiz R (Org). Pierre Bourdieu: sociologia. Coleção Grandes Cientistas Sociais. ED Ática: São Paulo.1994.

3. Carvalho EC, Laus EL, Caliri MHL, Rossi LG. Da produção a utilização de resultados de pesquisa na prática assistencial: uma experiência em consolidação. In: Rev Bras Enferm. 2010; 63(5): 853-8.

4. Giffin K. Produção do conhecimento em um mundo "problemático": contribuições de um feminismo dialético e relacional. Rev. Estud. Fem. 2006; 14(3): 635-653.

5. Caliri MHL. A utilização da pesquisa na prática clínica de enfermagem: limites e possibilidades [tese de livre-docência] Ribeirão Preto: Escola de enfermagem de Ribeirão Preto, Universidade de São Paulo; 2002.

6. Lopes MJM. O trabalho da enfermeira: nem público, nem privado, feminino, doméstico e desvalorizado. Rev Bras Enferm. 1988; 41(3/4): 211-7.

7. Meyer, D. Teorias e políticas de gênero: fragmentos históricos e desafios atuais. Rev Bras Enferm. 2004; 57(1): 13-8.

8. Brasil. Presidência da República. Secretaria Especial de Políticas para as Mulheres. Pensando gênero e ciência. Encontro Nacional de Núcleos e Grupos de Pesquisas - 2005, 2006/ Presidência da República. - Brasília: Secretaria Especial de Políticas para as Mulheres, 2006.

9. Aquino EML. Gênero e ciência no Brasil: Contribuições para pensar a ação política na busca da equidade. En: Brasil. Presidência da República. Secretaria Especial de Políticas para as Mulheres. Pensando gênero e ciência. Encontro Nacional de Núcleos e Grupos de Pesquisas - 2005, 2006/ Presidência da República. - Brasília: Secretaria Especial de Políticas para as Mulheres, 2006. p. 11-21.

10. Markus M. Mulheres, êxito e sociedade civil: submissão a ou subversão do princípio de realização? En: Benhabib S; Cornell D. Feminismo como crítica da modernidade. RJ: Rosa dos Tempos. 1987. 